\title{
Mobilidade sustentável: o uso da bicicleta como meio de transporte em Maringá, PR, Brasil
}

\author{
Movilidad sostenible: el uso de la bicicleta como medio de \\ transporte en Maringá, PR, Brasil
}

\section{Sustainable mobility: the use of bikes as a transport in Maringá, PR, Brazil}

\author{
Queli Cunha de Lima Pedro \\ queli_de_lima@hotmail.com \\ Universidade Estadual de Maringá, UEM, Maringá, PR
}

Ricardo Massulo Albertin

prof.ricardo@feitep.edu.br

Faculdade de Engenharia e Inovação Técnico Profissional, FEITEP, Maringá, PR

Hugo Gabriel Fernandes Viotto

enghugo.orbe@gmail.com

Universidade Estadual de Maringá, UEM, Maringá, PR

\begin{abstract}
Resumo: Este trabalho analisou o perfil dos ciclistas que utilizam as ciclovias e ciclofaixas na cidade de Maringá, sua motivação para adoção da bicicleta como meio de transporte e suas opiniões para ações de melhoria. Foi realizada entrevista estruturada formal com 51 ciclistas, maioria homens entre 21 e 50 anos, que utilizam a bicicleta para ir e voltar do trabalho e realizar práticas esportivas e de lazer. Para a grande maioria dos entrevistados, a construção de mais ciclovias e ciclofaixas resultaria em uma maior adoção de bicicleta e uso da malha cicloviária na cidade.
\end{abstract}

Palavras-chave: Cidades sustentáveis; Engenharia urbana; ciclovias e ciclofaixas

Resumen: Este trabajo analizó el perfil de los ciclistas que utilizan los carriles bici y ciclo pistas en la ciudad de Maringá, su motivación para adoptar la bicicleta como medio de transporte y sus opiniones para acciones de mejora. Se realizó una entrevista formal estructurada con 51 ciclistas, la mayoría hombres de entre 21 y 50 años, que utilizan la bicicleta para ir y regresar del trabajo y realizar prácticas deportivas y de ocio. Para la gran mayoría de los encuestados, la construcción de más carriles de bicicletas y carriles bici resultaría en una mayor adopción de la bicicleta y el uso de la malla de ciclovía en la ciudad.

Palabras clave: Ciudades sostenibles; Ingeniería urbana; ciclovias e ciclofaixas

Abstract: This work analyzed the profile of cyclists who use the cycle lanes and cyclotracks in the city of Maringá, their motivation to adopt the bicycle as a means of transportation and their opinions for improvement actions. A formal structured interview was conducted with 51 cyclists, most men between 21 and 50 years old, who use the bike to go and return from work and perform sports and leisure practices. For 
most respondents, the construction of more bike lanes and cycle tracks would result in a greater adoption of bicycle and use of the cycle-road mesh in the city.

Keyword: Sustainable cities; Urban engineering; Cycling; Cycle paths.

\section{INTRODUÇÃO}

De acordo com Chichilnisky e Heal (1998, apud MINKEN; SAMSTAD; PUTZ, 2001) o termo sustentabilidade pode ser caracterizado em dois aspectos relevantes, tanto como vinculado ao bem-estar de uma sociedade atual, quanto de uma sociedade futura. Somado a isto, os autores definem o termo como a conservação dos recursos naturais, entretanto, em ambos os casos, existe a preocupação com o impacto dos planos e das políticas atuais no âmbito da mobilidade urbana (ANGEOLETTO et al., 2019; RUMBLE et al., 2019).

Mais especificamente, a terminologia sustentabilidade pode ser compreendida como um modelo de desenvolvimento que acate as necessidades da geração atual sem que comprometa a possibilidade das gerações futuras satisfazerem suas necessidades, desta forma, o estudo em diversas áreas e setores de uma sociedade para implementação de meios sustentáveis vem sendo cada vez mais difundido globalmente (PLUME, 2003; ANGEOLETTO et al., 2016).

Dentre alguns temas vinculados aos meios sustentáveis, pode-se citar a mobilidade urbana, que é capaz de ser alcançada sob dois enfoques principais: um primeiro relacionado à oferta do transporte em uma dada situação socioeconômica, e outro aspecto concernente à qualidade ambiental (CAMPOS, 2004). Entretanto, existem dificuldades fora do alcance do poder público para a implementação de ciclofaixas em meios urbanos. De acordo com Wardman, Tight e Page (2007), as pessoas tenderão a utilizar a bicicleta como meio de transporte apenas quando se sentirem mais seguras em seu trajeto, distante do tráfego motorizado.

Deste modo, o estudo objetivou identificar os problemas pertinentes à implantação de ciclofaixas em ambiente urbano da cidade de Maringá. Para isso, foi realizada uma análise do perfil dos ciclistas que fazem uso deste modal e o que os motiva a utilizar a bicicleta como meio de transporte. Também se questionou-se quais seriam outros fatores, além da construção de ciclovias e ciclofaixas, a influenciar na adoção de bicicletas como meio de transporte diário pelos cidadãos maringaenses.

\section{REVISÃO BIBLIOGRÁFICA}

Como um molde natural urbano há décadas, as cidades brasileiras estruturam sua malha viária em prol do tráfego motorizado e não em favor das pessoas que ali vivem. $\mathrm{O}$ crescimento urbano das cidades, somado às políticas governamentais de incentivo a indústria automobilística têm contribuído para o aumento na dependência do automóvel. Argumenta-se que o automóvel promove ao cidadão eficiência no deslocamento com 
desempenho de velocidade atingindo o destino com menor tempo, disponibilidade de uso, privacidade, comodidade, controle de localização, segurança, conforto e status pessoal (DENNIS, 2007).

Segundo o Ministério do Transporte e da Mobilidade Urbana das Cidades (BRASIL, 2007) o processo acelerado de urbanização ausente de planejamento integrado entre as políticas de desenvolvimento urbano, transportes, mobilidade, controle do uso e da ocupação do solo resultou em segregação socioespacial e intervenções urbanas pontuais, prejudicando o deslocamento dos cidadãos nas cidades, e as muitas infraestruturas geradas foram apropriadas pelos veículos motorizados.

Com a atual realidade do trânsito urbano nas grandes e médias cidades no Brasil, elevam-se as discussões em relação aos congestionamentos, a segurança viária e à imensa quantidade de gases poluentes gerados pelos veículos automotivos. Mudanças nos padrões de deslocamento da população por meio da adoção de transportes não motorizados resultariam na construção de centros urbanos com melhor qualidade de vida (MARQUES FILHO, 2007).

Um estudo realizado pela Secretaria Nacional de Transporte e da Mobilidade Urbana (SeMob) nas cidades brasileiras, constatou o crescente uso da bicicleta como meio de transporte para atividades de lazer, de trabalho e estudo, e considerou a necessidade de dar a este meio de transporte o tratamento adequado ao papel que ele desempenha nos deslocamentos urbanos. Desta forma, em 2007, o Ministério das Cidades (MCidade) lançou o Programa Bicicleta Brasil, um caderno de referência para a elaboração do Plano de Mobilidade por bicicleta nas cidades (PlanMob). Esta iniciativa foi fruto de uma campanha envolvendo a participação de toda a sociedade brasileira, que em 2003 realizou a $1^{a}$ Conferência das Cidades objetivando criar o Conselho das Cidades (ConCidades). Foram delineados princípios e diretrizes da Política Nacional de Desenvolvimento Urbano PNDU, dentre eles o de Transporte e Mobilidade Urbana, onde a Resolução no 07/2004, gerador do Programa Nacional de Mobilidade por Bicicleta, Bicicleta Brasil, instituiu a Portaria n $n^{0} 399 / 2004$ que emitiu orientações e recomendações para o conteúdo mínimo do Plano Diretor Transporte e do PlanMob. Este é obrigatório para cidades com mais de 500 mil habitantes, fundamental e indispensável para todos os municípios, priorizando o transporte coletivo, os não motorizados e o pedestre.

A Política Nacional de Mobilidade Urbana, Lei no 12.587/2012 (BRASIL, 2012) é, portanto, instrumento da política de desenvolvimento urbano que também trata do modo de transporte urbano não motorizado, garantindo a construção de ciclovias para a mobilidade urbana das bicicletas contribuído com o desenvolvimento sustentável das cidades nas dimensões socioeconômicas e ambientais.

O Ministério do Transporte e da Mobilidade Urbana das Cidades (BRASIL, 2007) esclarece que a inserção da bicicleta nos deslocamentos urbanos deve ser tratada como um caminho para a introdução do conceito de mobilidade urbana em cidades que almejam o desenvolvimento sustentável como forma de inclusão social, contenção e extinção de agentes poluentes e melhoria da saúde da populacional. Boareto (2010) acrescenta que o uso da bicicleta é um importante fator de reordenação, reconfiguração do espaço urbano e 
social, bem como um vetor de melhoria ambiental, considerando seu tamanho e a ausência de emissão de gases nocivos ao meio ambiente. Para isso deve ser pensado em um novo desenho urbano, que agregue a implantação de infraestruturas, bem como a cogitação sobre o uso e a ocupação do solo urbano.

Embora a bicicleta seja um transporte que ocupe pouco espaço para trafegar e seja um meio de transporte sustentável, em grande parte da realidade das cidades brasileiras, ela precisa disputar o espaço viário com os meios de transportes motorizados (automóveis, mostos, caminhões, ônibus) na ausência da ciclovia ou ciclofaixa. A baixa velocidade das bicicletas e a imprudência por parte dos motoristas e dos ciclistas, são alguns motivos de atrito entre as duas modalidades de transporte. A implantação de ciclovias e ciclofaixas são soluções para a redução desses atritos, e principalmente, promoção de segurança aos ciclistas (MARQUES FILHO, 2007). Compete ao poder público promover segurança aos ciclistas concedendo espaços viários de condições humanas ao trânsito. A reorganização dos espaços e do sistema viário precisa ser mais humana, equilibrada, segura e conforme os requisitos ambientais.

No ano de 2013 iniciou-se a análise pela Comissão Especial de Estudo para Implantação de Ciclovias com o intuito de viabilizar políticas públicas favoráveis para o incentivo do uso da bicicleta em Maringá. Conforme explicado pelo secretário de Planejamento, no site da Prefeitura de Maringá (PM Maringá, 2018), o projeto atende a Lei de Mobilidade Urbana (BRASIL, 2012), o qual da prioridade aos modais não motorizados (pedestres e ciclistas), visto a divulgação de que Maringá havia superado Curitiba (a capital do estado) em número de veículos por habitante. Ainda de acordo com o site da Prefeitura de Maringá, em 2014 havia no município aproximadamente $15 \mathrm{~km}$ de ciclovias. Atualmente a cidade conta com uma malha cicloviável de 87 Km, existentes e em execução (PM Maringá, 2018).

\section{MATERIAIS E MÉTODOS}

Como referência, utilizou-se como método a adaptação do modelo apresentado na Coleção Bicicleta Brasil: Programa Brasileiro por mobilidade com Bicicleta - Caderno 1: Caderno de Referência para Elaboração de Plano de Mobilidade por Bicicletas na Cidade (BRASIL, 2007). Este Plano de Mobilidade traz referências, diretrizes e requisitos para os municípios incentivarem a circulação de meios de transporte não motorizado urbano, contribuindo para um desenvolvimento sustentável da cidade, inserindo e ampliando o transporte de bicicleta, estimulando os municípios a implantar sistemas cicloviários e implementando no desenho urbano os transportes não motorizados.

\section{Caracterização da área de estudo}

A área de estudo localiza-se na cidade de Maringá, estado do Paraná, Sul do Brasil (Fig. 1), emancipada como município em 1951, resultado de um projeto de colonização implantado pela Companhia de Terras Norte do Paraná. Atualmente o município possui 
população estimada de aproximadamente 417.010 habitantes e uma área territorial de $487,052 \mathrm{~km}^{2}$ (IBGE, 2018).

Figura 1: Localização da cidade de Maringá, PR.

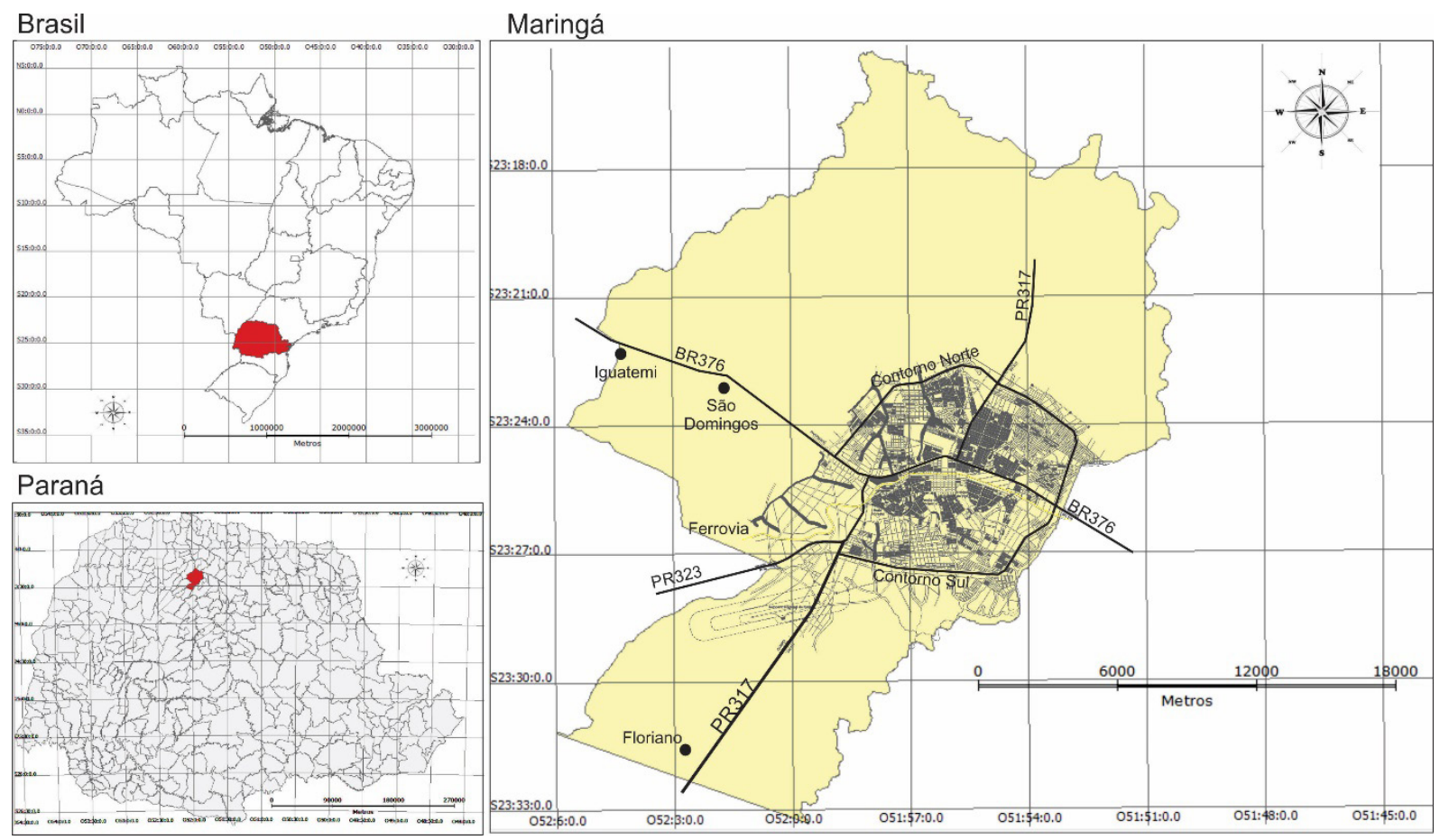

Fone: os autores.

Na Figura 2 é possível constatar toda a extensão abrangida por ciclovias e ciclofaixas no município, construída ou em fase de projeto. A cidade possui $33 \mathrm{Km}$ de vias concluídas destinadas a ciclistas e, até o final do ano de 2019 totalizará mais $50 \mathrm{Km}$.

Para realização desta pesquisa, definiu-se como área de levantamento in loco, um trecho da ciclofaixa e ciclovia intitulada Mandacaru, no trecho delimitado entre Praça Pion. Jacinto Ferreira Branco e Praça 7 de Setembro, com extensão de 2.200 m (Fig. 3). Este trecho foi escolhido para análise devido ao elevado fluxo de ciclistas e ao potencial desta área, com grande foco do comércio. 
Figura 2: Ciclovias e ciclofaixas existentes na cidade de Maringá, PR.

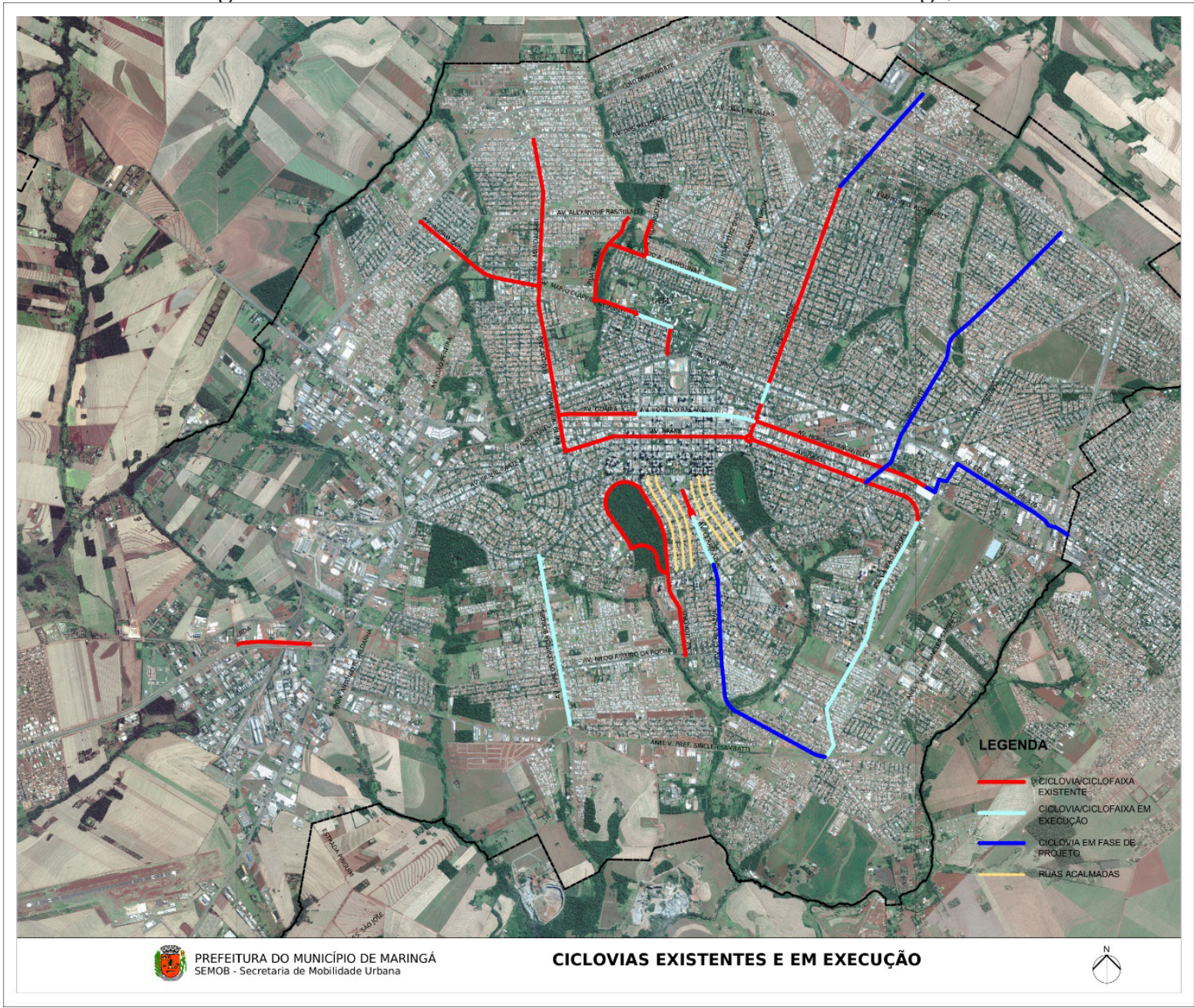

Fonte: Secretaria de Mobilidade Urbana do município de Maringá, 2018.

O estudo das ciclovias e ciclofaixas no trecho delimitado pela pesquisa, enquanto avaliação, pressupõe três pontos de análise: (1) registro quantitativo do fluxo de ciclistas; (2) avaliação qualitativa; (3) observação in loco.

Realizou-se a contagem volumétrica dos ciclistas em dois pontos distintos, durante duas horas, em períodos diferentes, constatando o fluxo de ciclistas que utilizam a ciclovia no trecho delimitado entre as Praças Pioneiro Jacinto Ferreira Branco e Sete de Setembro, no horário de pico. A coleta de dados, nos dois pontos distais da ciclovia, foi realizada no mês de outubro 2018 nos períodos matutino (07:00 - 09:00) e vespertino (17:00 - 19:00). 
Figura 3: Localização da área de pesquisa, Maringá, PR.

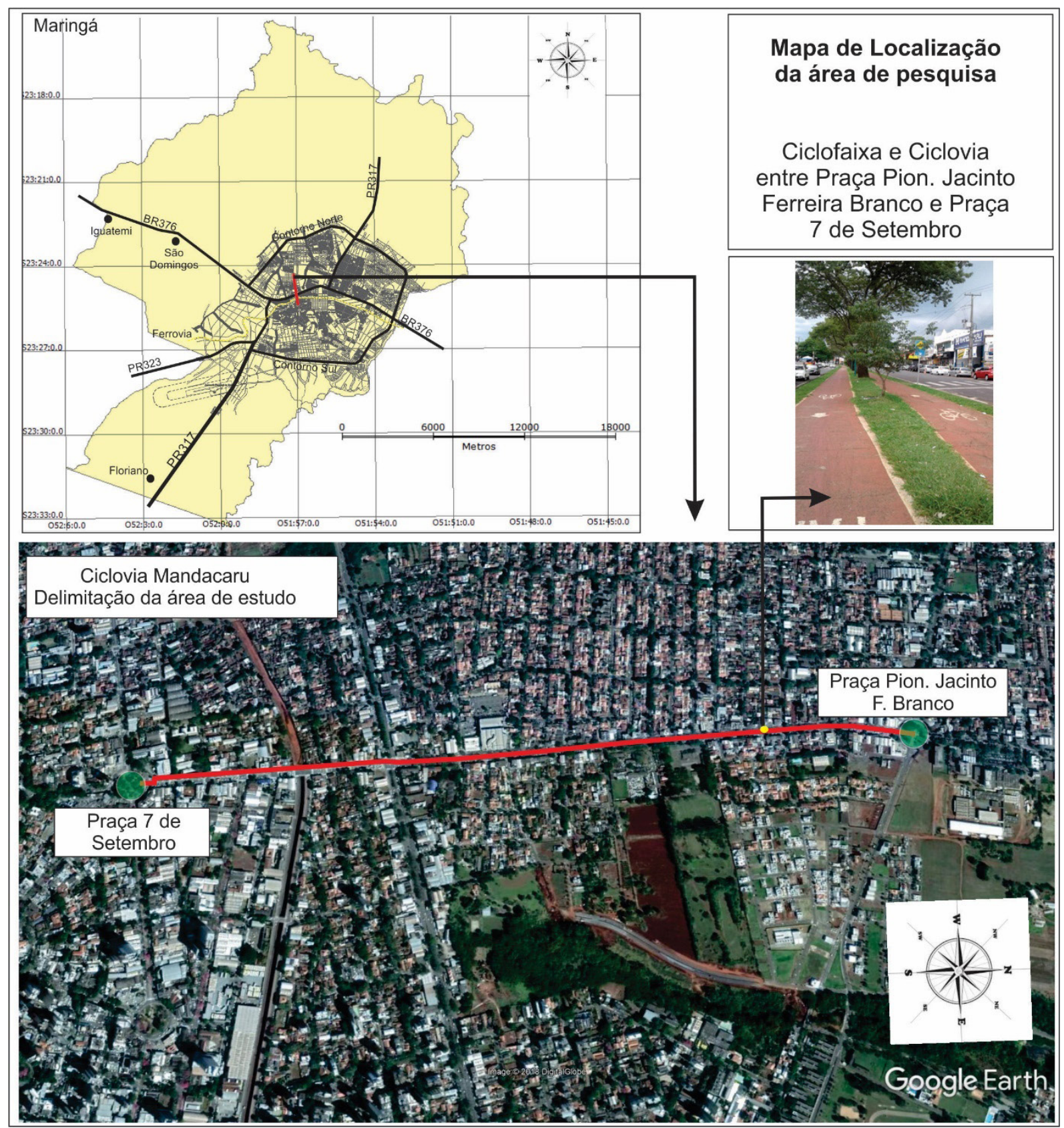

Fonte: os autores.

$\mathrm{Na}$ abordagem qualitativa realizou-se entrevista padronizada com os ciclistas, com amostragem aleatória de 51 entrevistados, pela qual buscou-se compreender o cotidiano e o perfil dos ciclistas.

Para levantamento do perfil, a motivação para o uso da bicicleta e a opinião dos ciclistas como contribuição e melhoria no aumento do uso da malha viária, foram aplicadas oito questões referentes a gênero e faixa etária, bairro de residência, finalidade e uso e periodicidade. Também foi averiguado se o usuário percorria todo seu trajeto de destino sobre as ciclovias e ciclofaixas. Por fim, a última questão estimulava os ciclistas a dar sua 
opinião sobre o que poderia ser implantado pela municipalidade para aumentar o uso de bicicleta, tornando esta modalidade de transporte mais convidativa no dia-a-dia dos cidadãos maringaenses.

\section{RESULTADOS E DISCUSSÕES}

Foram amostrados 590 ciclistas, sendo 507 homens (86\%) e apenas 83 do sexo feminino. Observa-se na Tabela 1, que no período vespertino há um aumento do número de ciclistas em aproximadamente $24 \%$. Tal fato pode estar associado diretamente à prática de atividades físicas e ao lazer utilizando este modal, mais especificamente, a partir das 18 horas, período no qual as pessoas rotineiramente já teriam finalizado suas obrigações diárias.

Tabela 1: registro quantitativo do fluxo de ciclistas na ciclovia Mandacaru, Maringá, PR.

\begin{tabular}{|c|c|c|c|c|}
\hline Local & Período & Horário & Masculino & Feminino \\
\hline \multirow{6}{*}{$\begin{array}{l}\text { Praça Pioneiro Jacinto Ferreira Branco } \\
\text { (ligação das ciclovias da Avenida } \\
\text { Mandacaru e da Alziro Zarur) }\end{array}$} & \multirow{2}{*}{ Manhã } & 7:00 às 8:00 & 72 & 15 \\
\hline & & 8:00 às 9:00 & 29 & 03 \\
\hline & \multicolumn{2}{|c|}{ Total } & 101 & 18 \\
\hline & \multirow{2}{*}{ Tarde } & $17: 00$ às $18: 00$ & 55 & 15 \\
\hline & & 18:00 às 19:00 & 87 & 11 \\
\hline & \multicolumn{2}{|c|}{ Total } & 142 & 26 \\
\hline \multirow{6}{*}{$\begin{array}{c}\text { Praça } 7 \text { de Setembro (ligação das } \\
\text { ciclovias da Avenida Mandacaru e da } \\
\text { Avenida Brasil }\end{array}$} & \multirow{2}{*}{ Manhã } & 7:00 às 8:00 & 90 & 13 \\
\hline & & 8:00 às 9:00 & 33 & 8 \\
\hline & \multicolumn{2}{|c|}{ Total } & 123 & 21 \\
\hline & \multirow{2}{*}{ Tarde } & 17:00 às 18:00 & 57 & 10 \\
\hline & & 18:00 às 19:00 & 84 & 08 \\
\hline & \multicolumn{2}{|c|}{ Total } & 141 & 18 \\
\hline & \multicolumn{2}{|c|}{ Total geral } & 507 & 83 \\
\hline
\end{tabular}

Fonte: os autores.

Na pesquisa qualitativa, observou-se que a maioria dos usuários está na faixa entre 21 e 35 anos, embora uma parte substancial esteja na faixa de 36 e 50, ou mais de 50 anos. No entanto, é nítido ainda que o gênero masculino predomina sobre o feminino no uso da bicicleta como meio de transporte. Ao todo foram entrevistados 44 ciclistas do gênero masculino e 7 femininos, entre as quais 4 ciclistas na faixa superior a 50 anos de idade (Fig. 4). 
Figura 4: Perfil de faixa etária e gênero dos ciclistas usuários da ciclovia e ciclofaixa Mandacaru.

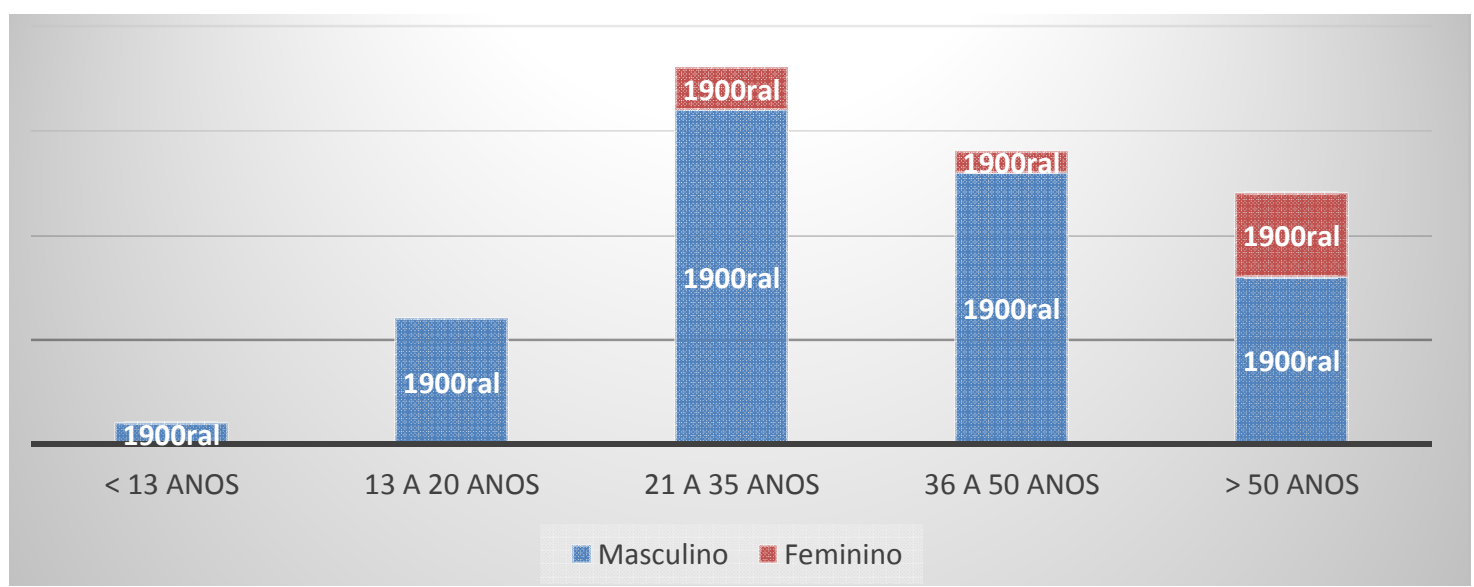

Fonte: os autores.

Observou-se que 61\% dos usuários utilizam a modal bicicleta todos os dias da semana, ou seja, de segunda-feira a domingo, em segundo lugar $17 \%$ que alegaram utilizar durante cinco dias da semana, sendo de segunda à sexta-feira (Fig. 5). Tais números se justificam pela grande parcela de usuários deste modal que o utilizam para se dirigir ao seu trabalho ou estudo nos dias úteis da semana, enquanto aos sábados e domingos possivelmente o fluxo de bicicletas permanece elevado principalmente pela prática de atividades físicas e também por lazer.

Figura 5: periodicidade de uso durante a semana.

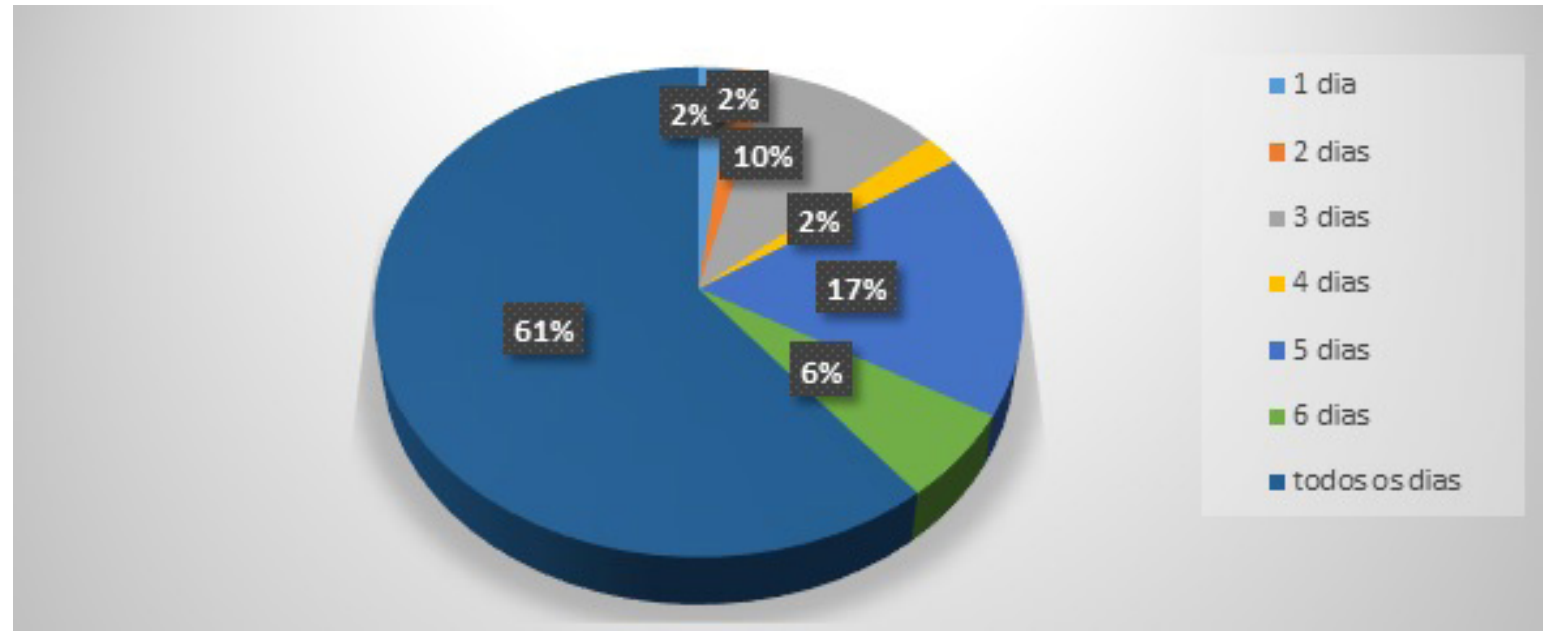

Fonte: os autores.

Comprovando a observação anterior, 57\% dos entrevistados utiliza a bicicleta para ir e voltar do trabalho, seguido do uso esportivo e para lazer, ambos com $15 \%$ cada um, e por último os 13\% de usuários que utilizam o modal para ir estudar (Fig. 6). 
Figura 6: Finalidade do uso da bicicleta pelos usuários da ciclovia e ciclofaixa

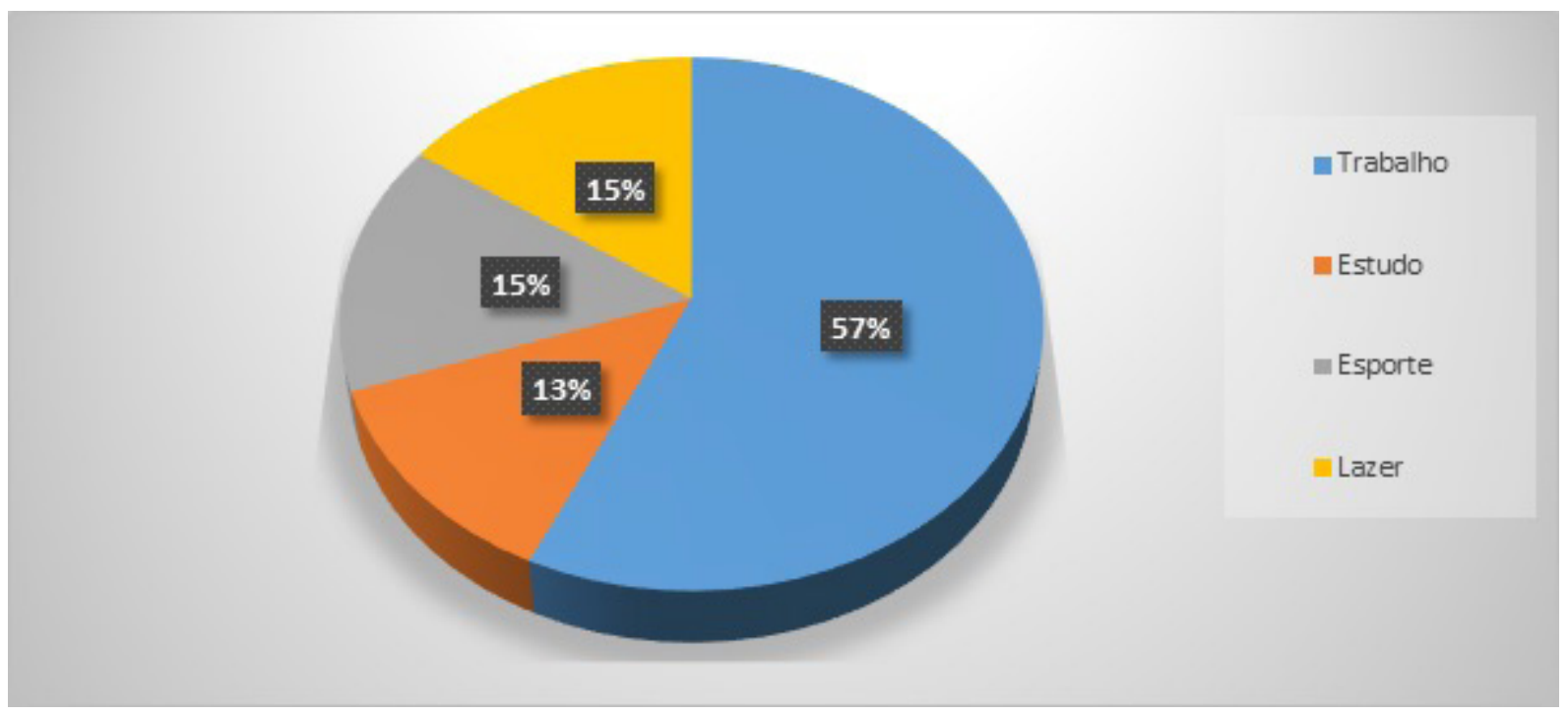

Fonte: os autores

Em relação à existência de malha cicloviária no trajeto percorrido pelos usuários, contatou-se que para $78 \%$ não há ciclovia e ciclofaixa em todo o trajeto. Isso demonstra que a estrutura urbana de ciclovias e ciclofaixas, mesmo com a expansão verifica nos últimos anos, ainda está aquém de atender à todos, ainda que exista um grande segmento de ciclofaixa e ciclovia na Avenida Mandacaru, a queixa dos usuários refere-se à falta de conexão de trechos de ciclovias e ciclofaixas na Avenida Mandacaru com bairros residenciais, onde se concentra grande parte dos usuários deste modal. Sendo assim, a não existência de infraestrutura para utilização de bicicleta em ruas intermediárias sujeita os ciclistas a diversos riscos, dentre eles a possibilidade de serem atropelados por outros veículos, ou de colidirem com obstáculos na trajetória devido à falta de sinalização, entre outros.

Complementando a questão anterior, observa-se na Figura 7 que a maior concentração de usuários provém de bairros próximos à ciclovia da faixa estudada, tais como Zonas 05, 06 e 07, Jardim das Laranjeiras, Santa Izabel, Ney Braga e Vila Vardelina, correspondendo a 37\% dos entrevistados. Os demais provêm de diversos bairros na cidade. 
Figura 7: Cidade ou bairro de origem do ciclista

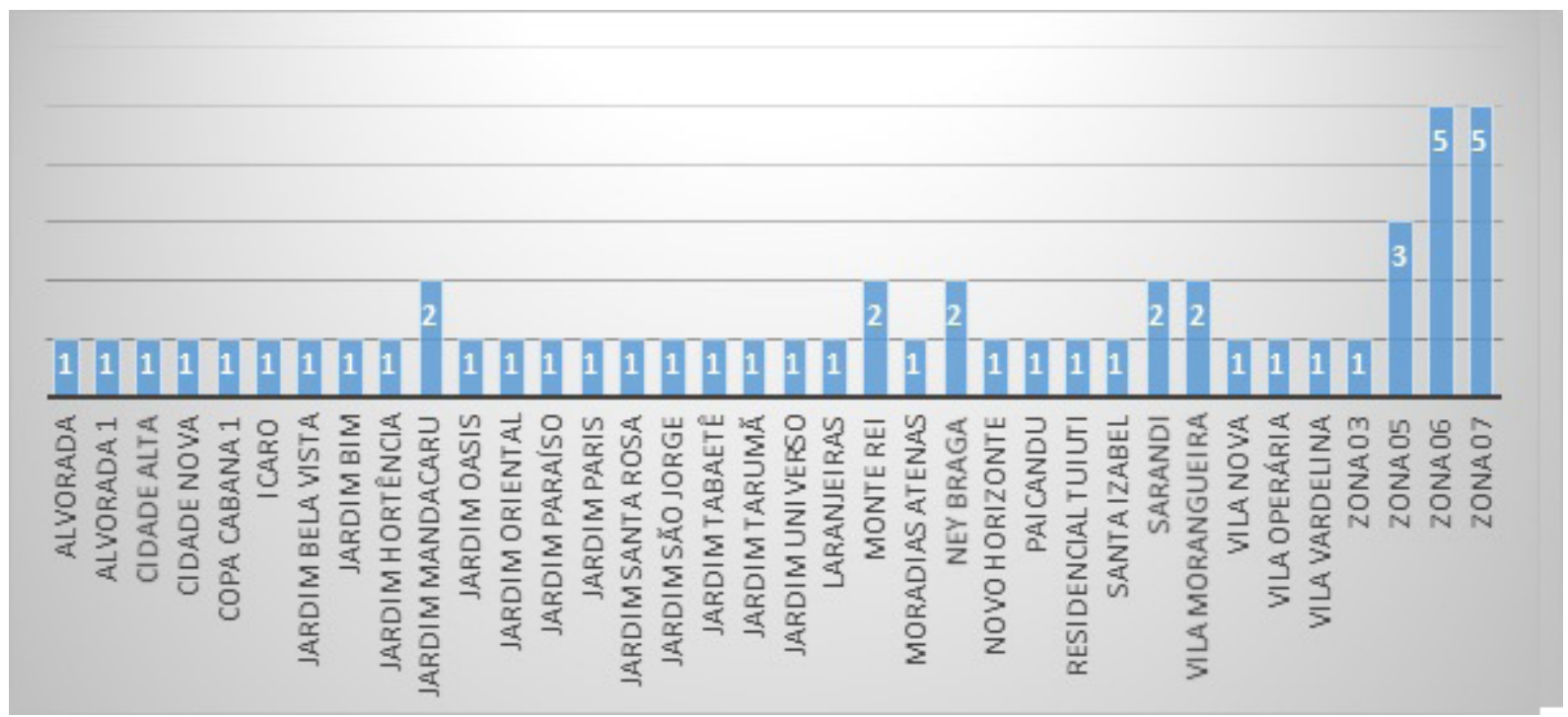

Fonte: os autores.

Em relação ao motivo do entrevistado a adotar a bicicleta como meio de transporte em seu dia-a-dia (Fig. 8), observou-se que $25 \%$ dos entrevistados se motiva ao uso da bicicleta para melhoria da saúde e $24 \%$ são motivados pela economia que o transporte proporciona e insatisfação com o transporte público (7\%). Os demais se distribuem por preocupação com o condicionamento físico (16\%); cuidado com o meio ambiente (11\%) e residência nas proximidades (2\%). Enquanto 15\% foram motivados pela própria existência da ciclovia e ciclofaixa.

Figura 8: Principais motivações para uso da bicicleta

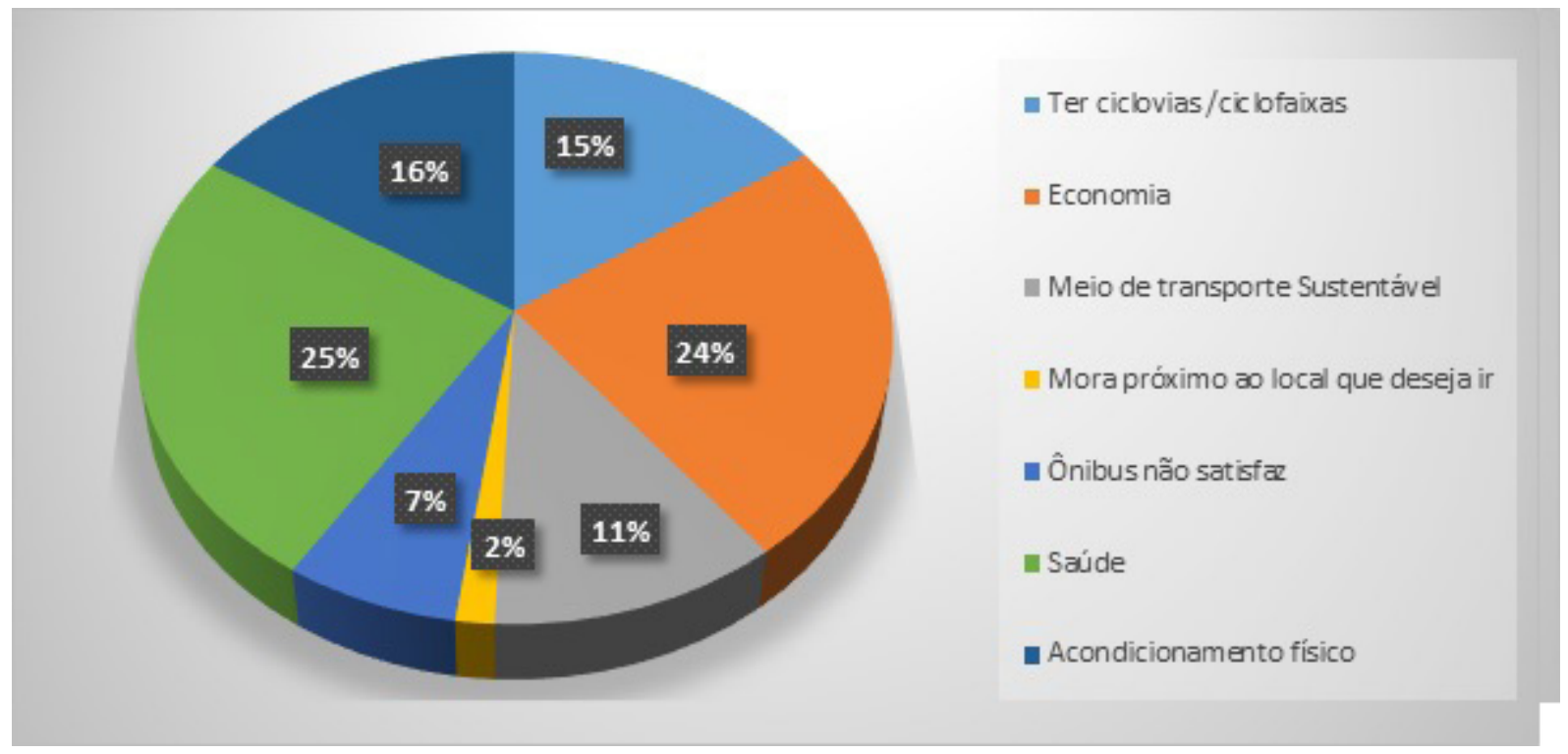

Fonte: os autores. 
Em relação ao questionamento sobre o que poderia ser implantado pelo município para incentivar o maior uso da bicicleta pelos cidadãos (Fig. 9), 40\% dos entrevistados apontou que a construção de mais ciclovias e ciclofaixas contribuiria no aumento do número de ciclistas no dia-a-dia da cidade, enquanto para $20 \%$ a instalação e/ou reconfiguração de semáforos que abrissem segundos antes para os ciclistas aumentaria a segurança (outros $9 \%$ apontaram melhorias na segurança sem especificar o quê). O uso de sistemas de locação coletivo de bicicletas foi apontado em $13 \%$ das respostas, bem como a implementação bicicletários (2\%) e duchas e vestiários nas empresas (8\%). As demais opiniões se referem à proibição de pedestres caminhando sobre as ciclovias (4\%), manutenção e limpeza das ciclovias/ciclofaixas existentes $(2 \%)$ instalação de mais semáforos em cruzamentos e rotatórias (1\%) e elaboração de lei para que novos loteamentos possuíssem na parte de infraestrutura a construção de ciclovia ou ciclofaixa na rua principal (1\%).

Vale ressaltar que todos esses aspectos listados se relacionam diretamente com a segurança, tanto dos ciclistas quanto dos pedestres, seja pelo aumento das ciclovias e ciclofaixas, seja pela implantação de tecnologias que favorecem um trânsito mais seguro para os mesmos, como o semáforo exclusivo destinado a portadores de bicicletas.

Figura 9: Opinião sobre o que poderia ser implantado pelo município para aumentar o uso da bicicleta pelos usuários.

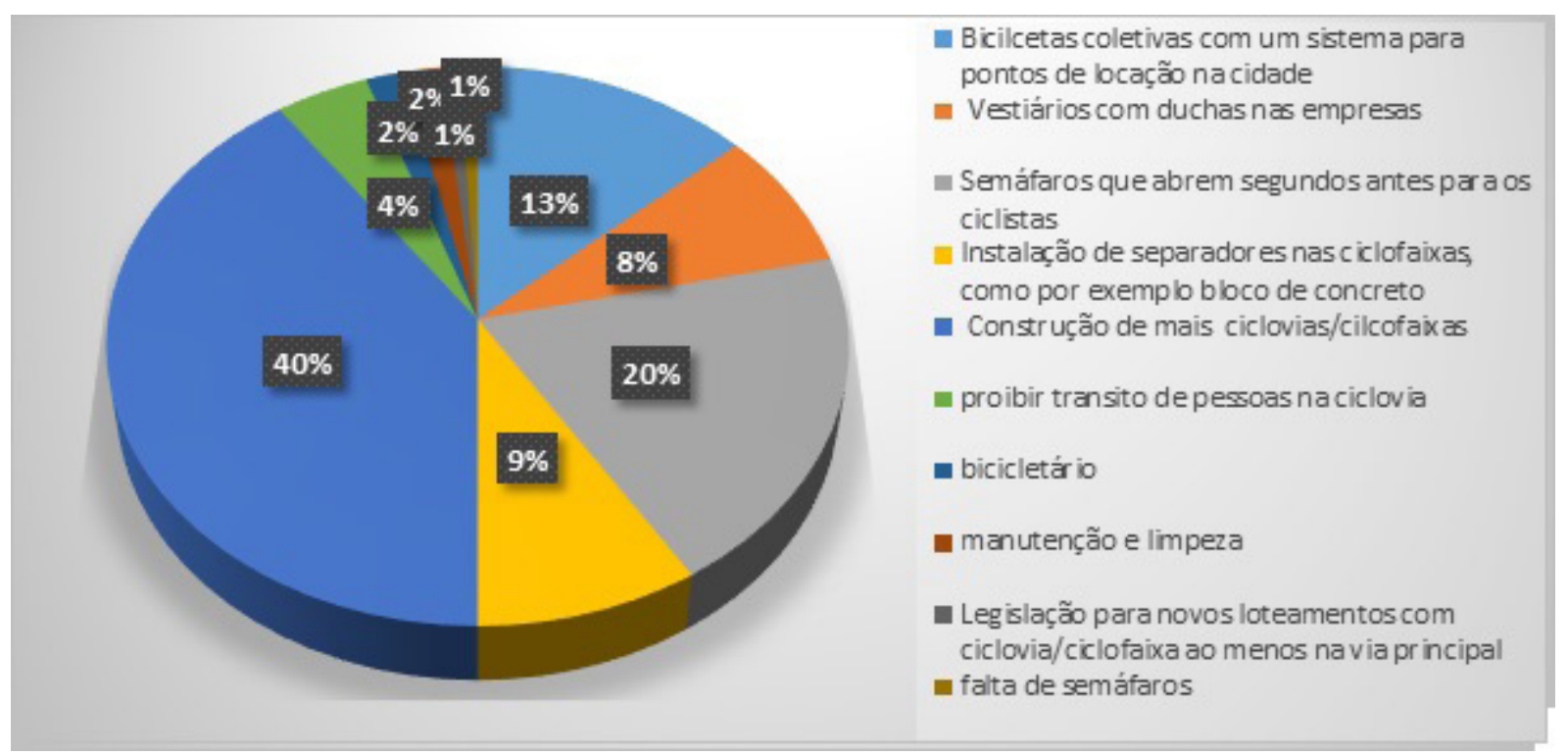

Fonte: os autores.

A opinião dos usuários foi comparada com a infraestrutura atual da ciclovia/ ciclofaixa no trecho delimitado para a pesquisa. Observou-se em alguns pontos a presença de danos no pavimento, ausência de sinalização viária e de manutenção (Figs. 10 e 11). 
Figura 10: Vista parcial de danos no pavimento na ciclofaixa próximo à praça Sete de Setembro

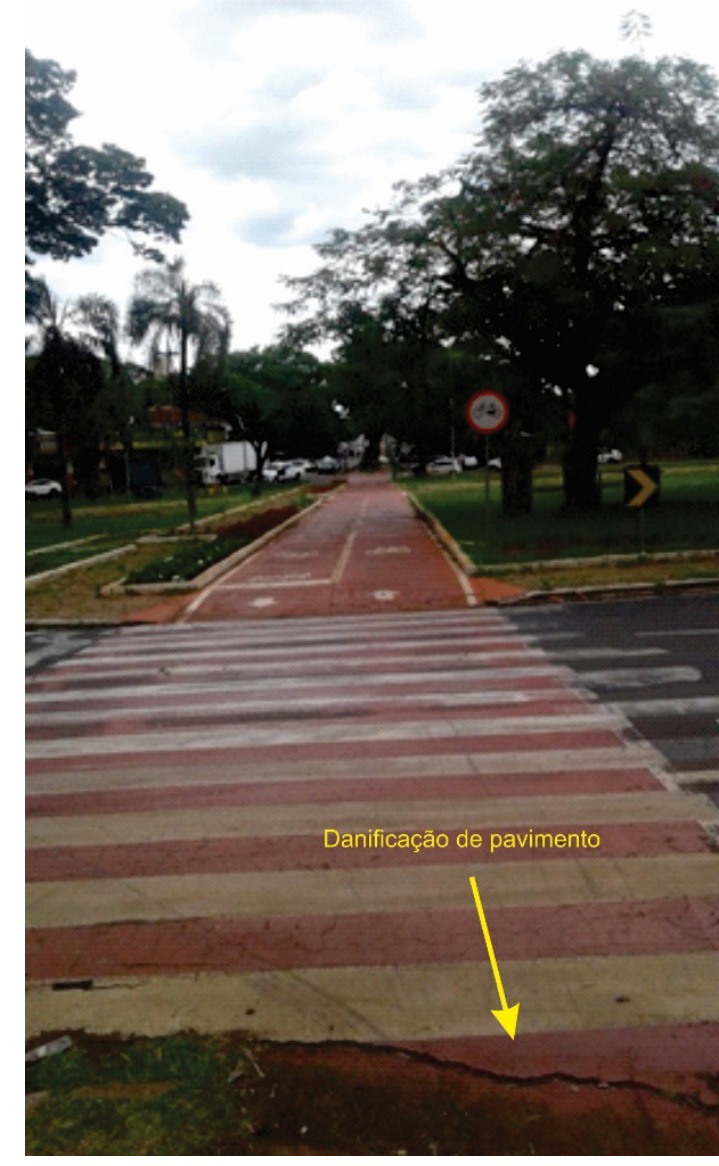

Fonte: os autores.
Figura 11: Ausência de manutenção na ciclovia Mandacaru, próximo à praça Sete de Setembro

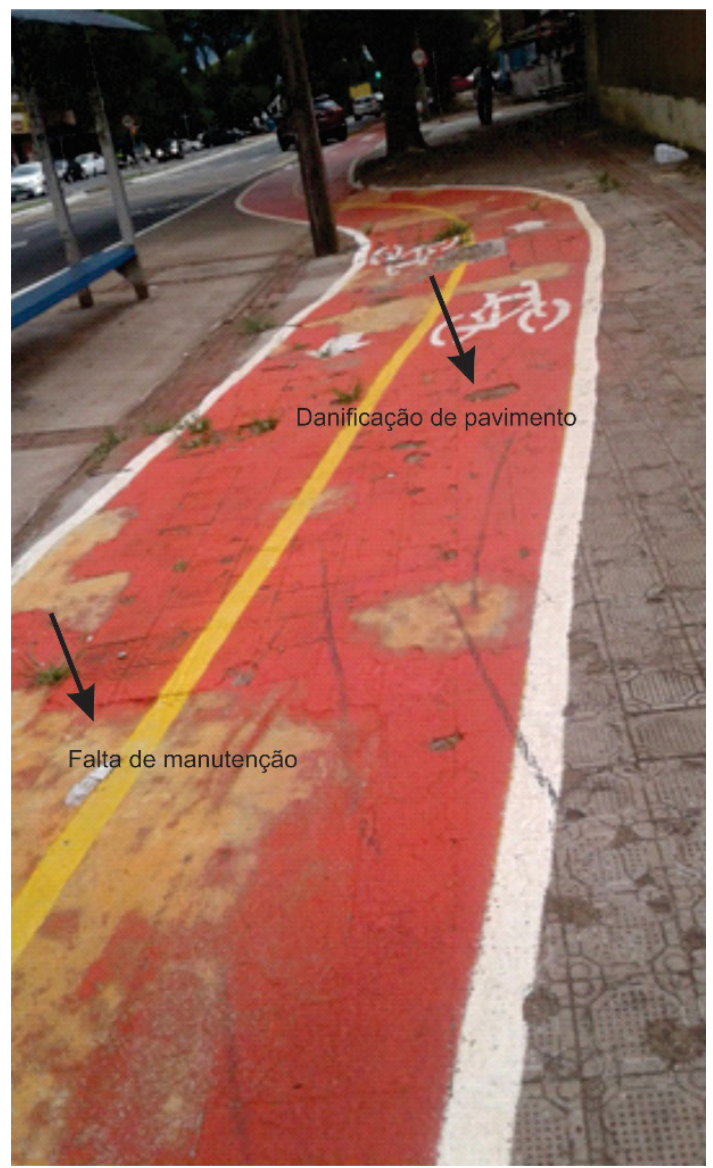

Fonte: os autores.

\section{CONSIDERAÇÕES FINAIS}

Cerca de metade dos entrevistados é motivado a adotar a bicicleta como meio de transporte pela preocupação com questões relacionadas à saúde, economia e ao acondicionamento físico. Apenas uma pequena parcela mostrou preocupação com o meio ambiente.

Há uma disparidade entre a percepção dos usuários e o que consta no planejamento do poder público, o de que o uso da bicicleta também tem como consequência benéfica de melhoria ao meio ambiente. O MCidade (2007) declara que a inserção da bicicleta como meio de transporte beneficia a saúde da população, a inclusão social e o meio ambiente.

Quanto as opiniões referentes ao o que poderia ser implantado pelo município para aumentar o uso de bicicleta pelos cidadãos no dia-a-dia da cidade, em primeiro lugar, com $40 \%$ das respostas, foi apontado a construção de mais ciclovias e ciclofaixas. Em segundo lugar a instalação de semáforos que abrem segundos antes para os ciclistas. Já em terceiro lugar a criação do uso de bicicletas coletivas com sistema de locação. Isto significa que o trecho de ciclovia/ciclofaixa estudado ainda carece de melhorias, precipuamente para 
medidas que tornem este trajeto mais seguro, tanto para os ciclistas, quanto para os demais automóveis e pedestres. Também foi apontada a necessidade da conexão das ciclovias e ciclofaixas situadas na avenida para adentro do bairro, isto é, a implantação em ruas periféricas.

Reafirmando Marques Filho (2007), de que a implantação de ciclovias e ciclofaixas são soluções de redução entre atritos os motoristas de veículos motorizados e de ciclistas, pois embora a bicicleta seja um transporte que ocupe pouco espaço, em grande parte da realidade das cidades brasileiras precisa disputar o espaço viário com os meios de transportes motorizados, causando insegurança aos usuários de bicicleta.

Embora a pesquisa realizada só tenha permitido a análise de uma pequena parte da malha viária que compõe a cidade de Maringá, seus dados podem ser representativos da realidade local. Espera-se que a pesquisa contribua para com que o município reveja e planeje ações a serem implantadas para elevar o número de pessoas que adotem a bicicleta como meio de transporte preferencial cotidiano na cidade. Diante dos dados expostos é de suma importância a participação do poder público no que concerne a implantação e ampliação de ciclovias e ciclofaixas no município de Maringá, tendo como consequência a promoção do desenvolvimento em diversos segmentos da cidade, dentre eles a saúde pública, o lazer, a minimização de impactos ao meio ambiente, a redução do custo com locomoção por parcela da população e outros.

\section{REFERÊNCIAS}

ANGEOLETTO, F. et al. Tipología socio-ambiental de las ciudades medias de Brasil: aportes para un desarrollo urbano sostenible. Urbe - Revista Brasileira de Gestão Urbana, v. 8, n. 2, p. 272-287, 2016.

ANGEOLETTO, F.; FELLOWES, M.D.; ESSI, L. et al. Ecología urbana y planificación: una convergéncia ineludible. Revista Electrônica em Gestāo, Educaçāo e Tecnologia Ambiental, n. 23, (e17), p. 1-7, 2019.

BRASIL. Ministério do Transporte e da Mobilidade Urbana das Cidades. Caderno de Referência para elaboração de Plano de Mobilidade por bicicletas na cidade. 2007. Disponível em: http:/ /www.intt.gob. ve/repositorio/biblioteca/texto_relacionados/Livro_20Bicicleta_20Brasil.pdf. Acesso em: 15 out. 2018.

BRASIL. Lei $\mathrm{n}^{0}$ 12.587, de 03 de janeiro de 2012. Institui as diretrizes da Política Nacional de Mobilidade Urbana. Disponível em:<http://www.planalto.gov.br/ccivil_03/_Ato2011-2014/2012/Lei/L12587.htm> Acesso em: 15 out. 2018.

BOARETO, R. A bicicleta e as cidades: como inserir a bicicleta na política de mobilidade urbana. 2.ed. São Paulo: IEMA, 2010.

CAMPOS, V.B. Uma visão da mobilidade urbana sustentável. Brasília: IPEA/Ministério das Cidades, 2004.

DENNIS, K. Cars, Cities, Futures. Lancaster: University Press, 2007.

IBGE - Instituto Brasileiro de Geografia e Estatística. Cidades. Disponível em:.www.ibge.gov.br Acesso em: 15 out. 2018.

MARQUES FILHO, J.M. Brasil, Pedalar Muito Ainda é Preciso. Transporte Cicloviário, v.7, p.128-131, 2007.

PLUME - Planning for Urban Mobility in Europe. Synthesis Report on Urban Sustainability and its Appraisal. 2003. 
PM Maringá. Prefeitura Municipal de Maringá. Disponível em: http://www2.maringa.pr.gov.br/site/ index.php?sessao $=4 b 784 c c d 3 d 554 b \& i d=23850$ Acesso em: 16 out. 2018.

MINKEN, H.; SAMSTAD, H.; PUTZ, O.K. PROSPECTS. Task 11 report : Proposal for objectives and indicators in urban land use and transport planning for sustainability. Oslo: TOI, 2001. Disponível em: https:// www.toi.no/publications / prospects-task-11-report-proposal-for-objectives-and-indicators-inurban-land-use-and-transport-planning-for-sustainability-article18071-29.html. Acesso em: 02 out. 2019.

RUMBLE, H.; ANGEOLETTO, F.; CONNOP, S. et al. Understanding and applying ecological principles in cities. In: LEMES DE OLIVEIRA, F.; MELL, I. (Eds.). Planning Cities with Nature: Theories, Strategies and Methods. Amsterdam: Springer Nature, 2019.

WARDMAN, M.; TIGHT, M.; PAGE, M. Factors influencing the propensity to cycle to work. Transportation research part a: Policy and practice, v. 41, n. 4, p. 339-350, 2007.

Data de submissão: 16/ abr./ 2019

Data de aceite: 19/ ago./ 2019 